\title{
IMPLEMENTASI ALGORITMA APRIORI UNTUK ANALISIS PENJUALAN DENGAN BERBASIS WEB
}

\author{
Agus Nursikuwagus \\ Fakultas Teknik, Program Studi Sistem Informasi \\ Universitas Komputer Indonesia \\ Email: agus235032@yahoo.com \\ Tono Hartono \\ Fakultas Teknik, Program Studi Sistem Informasi \\ Universitas Komputer Indonesia \\ Email: tnaia74@yahoo.co.id
}

\begin{abstract}
ABSTRAK
Transaksi penjualan merupakan suatu usaha penjualan yang dilakukan setiap menit, setiap hari, setiap minggu bahkan bertahun-tahun. Sehingga data akan semakin menumpuk bisa berasal dari proses manual maupun proses komputasi. Sehingga data yang ada belum dimanfaatkan dengan baik oleh pengambil keputusan. Tulisan ini bertujuan untuk memberikan laporan hasil penelitian mengenai implementasi algoritma apriori untuk analisis penjualan. Penelitian ini didukung dengan metodologi pengembangan perangkat lunak yang disebut linear incremental development. Pada proses yang dilakukan pada implementasi perangkat lunak ini terdapat beberapa langkah seperti penentuan masalah, identifikasi dan penyelesaian resiko, pengembangan dan test, serta perencanaan siklus berikutnya. Setiap langkah pada tahapan tersebut digunakan untuk memetakan permasalahan yang ada hingga terbentuknya suatu aplikasi sesuai kebutuhan. Sebagai hasil dari penelitian ini adalah aplikasi berdasarkan algoritma apriori yang terdiri dari pemilihan Itemset dan aturan asosiasi. Keluaran dari perangkat lunak ini digunakan untuk data acuan stok barang serta mengotomatisasi perhitungan analisis penjualan barang.
\end{abstract}

Kata kunci: sequential linear incremental, algoritma apriori, penjualan, implementasi.

\begin{abstract}
A sales transaction is activity business that can be made every minute, every day, every week or even years. Furthermore the data that have accumulated to be more complex, this process can be came from a manual process and the process of computing. The impact, the data have not been used by decision makers. This paper aims to provide research reports on the implementation of a priori algorithm for sales analysis. This research was supported by a software development methodology called linear incremental development. In the process performed on the implementation of this software, there are several steps such as determining the problem, identification and settlement risks, development and test, as well as planning the next cycle. Each step in this phase is used to map existing problems until the formation of a custom application. As a result of this research is the application based on the a priori algorithm consists of selecting Itemsets and association rules. The output of this software is used for reference data inventory and automate the calculation of sales analysis goods
\end{abstract}

Keywords: sequential linear incremental, algoritma apriori, selling, implementation.

\section{PENDAHULUAN}

Ketatnya persaingan pada sektor penjualan, membuat pelaku usaha harus pintar dalam menganalisis pasar. Selain itu, ketersediaan barang yang dijualpun menjadi salah satu faktor yang harus dianalisis supaya kebutuhan pelanggan dapat terpenuhi. Untuk mendukung hal itu, data penjualan sebelumnya dapat dimanfaatkan untuk menganalisis pasar dan kebutuhan pelanggan.

Penelitian sebelumnya yang dilakukan oleh Dewi Kartika Pane tentang Implementasi Data mining pada Penjualan Produk Elektronik dengan Algoritma Apriori (Studi Kasus: Kreditplus) menjelaskan analisis penjualan produk elektronik terutama laptop untuk mencari merk laptop yang banyak dibeli pelanggan. [3]

Algoritma apriori termasuk jenis aturan asosiasi pada data mining, algoritma apriori yang bertujuan untuk menemukan frequent item sets dijalankan pada sekumpulan data. Analisis apriori didefenisikan 
suatu proses untuk menemukan semua aturan apriori yang memenuhi syarat minimum untuk support dan syarat minimum untuk confidence. Penggunaan algoritma apriori yang telah dilakukan oleh peneliti sebelumnya [3], Hal ini menjadi dasar untuk membuat aplikasi data mining untuk analisis penjualan dengan algoritma apriori berbasis web dengan menggunakan data contoh (sampel data) dari Microsoft Adventure Work.

Berdasarkan latar belakang, maka dapat ditarik rumusan masalah yaitu bagaimana membuat aplikasi data mining untuk menganalisis penjualan dengan metode algoritma apriori berbasis web. Sedangkan batasan masalah dalam penelitian ini adalah sebagai berikut: bahwa aplikasi yang dikembangkan menggunakan algoritma apriori berbasis web, dan membahas mengenai algoritma apriori dapat diterapkan pada aplikasi data mining berbasis web. Tujuan dari penelitian ini adalah menyediakan data produk yang banyak dibeli oleh pelanggan sebagai data, sehingga dapat dilihat seberapa banyak pelangga membeli suatu produk yang dipengaruhi oleh produk lainnya. Pada akhirnya dapat mempermudahkan acuan stok barang serta mengotomatisasi perhitungan analisis penjualan barang.

\section{METODOLOGI PENELITIAN DAN LANDASAN TEORI}

\subsection{Metodologi Penelitian}

Di dalam pengembangan sistem selalu dibutuhkan acuan dan pedoman pengembangan, terdapat berbagai macam metodologi pengembangan perangkat lunak beserta kelebihan, kekurangan dan kecocokannya masing-masing terhadap suatu projek perangkat lunak.

Salah satu model pengembangan perangkat lunak yang merupakan evolusi dari model Linear Sequencial dan model pengembangan prototyping yang memiki kapasitas yang sangat baik dalam mengelola resiko kegagalan pengembangan perangkat lunak adalah pengembangan perangkat lunak dengan model spiral. Maka pengembangan sistem dalam penalitian ini menggunakan pendekatan pengembangan sistem spiral. Metodologi ini dapat dilihat pada gambar 1.

Model spiral adalah model proses pengembangan perangkat lunak yang diusung oleh Barry W. Boehm dengan model spiral, proses pengembangan perangkat lunak dikembangkan dalam serangkaian pengembangan incremental [2]. Selama awal iterasi, produk yang dihasilkan dapat menjadi sebuah purwarupa yang dapat menjadi acuan pengembangan berikutnya. Model spiral memiliki tiga hingga enam region sebagai tahapan-tahapan proses pengembangan perangkat lunak. Setiap region merupakan sekumpulan kegiatan proses pengembangan perangkat lunak. Model spiral menggunakan purwarupa sebagai mekanisme pengurangan risiko kesalahan penangkapan kebutuhan. Sedangkan tools yang digunakan untuk merancang sistem ini adalah UML Unifed Modelling Language) dan menggunakan beberapa diagram dari UML tersebut, seperti: Use case Diagram, Class Diagram, dan Sequensial Diagram [1].

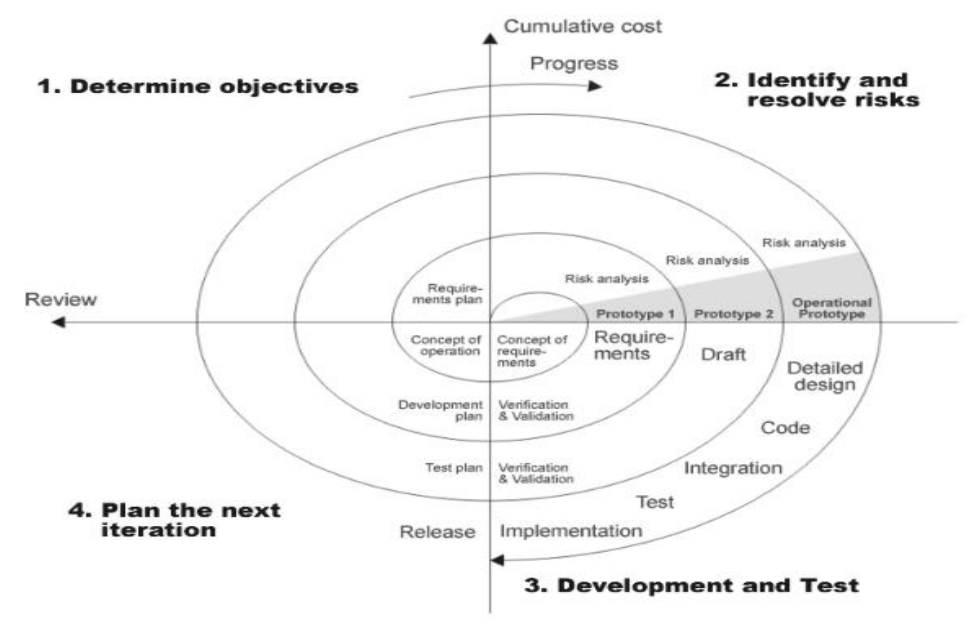

Gambar 1. Proses Pengembangan Spiral [2]

\subsection{Landasan Teori}

Data mining adalah suatu istilah yang digunakan untuk menguraikan penemuan pengetahuan didalam database. Data mining adalah proses yang menggunakan teknik statistik, matematika, kecerdasan buatan, dan machine learning untuk mengekstraksi dan mengidentifikasi informasi yang bermanfaat dan 
pengetahuan yang terkait dari berbagai database besar [3].

Algoritma apriori termasuk jenis aturan asosiasi pada data mining. Aturan yang menyatakan asosiasi antara beberapa atribut sering disebut affinity analysis atau market basket analysis. Analisis asosiasi atau association rule mining adalah teknik data mining untuk menemukan aturan suatu kombinasi item. Salah satu tahap analisis asosiasi yang menarik perhatian banyak peneliti untuk menghasilkan algoritma yang efisien adalah analisis pola frequensi tinggi (frequent pattern mining). Penting tidaknya suatu asosiasi dapat diketahui dengan dua tolak ukur, yaitu: support dan confidence. Support (nilai penunjang) adalah persentase kombinasi item tersebut dalam database, sedangkan confidence (nilai kepastian) adalah kuatnya hubungan antar-item dalam aturan asosiasi $[4,5,6]$.

PHP atau PHP (Personal Home Page) Hypertext Preprocessor merupakan bahasa pemrograman berbasis server-side yang banyak digunakan untuk membangun web dinamis atau situs web interaktif. Sebagai aturan umum, program PHP dapat dijalankan di server web, dan melayani halaman web untuk pengunjung berdasarkan permintaan. Salah satu fitur kunci dari PHP adalah dapat menanamkan kode PHP dalam halaman web HTML, sehingga sangat mudah untuk membuat konten dinamis dengan cepat [7]. Beberapa alasan menggunakan PHP [7], diantaranya sebagai berikut: performance, probabilitas, mudah digunakan, open-source, dukungan komunitas, dukungan aplikasi pihak ketiga.

$M y S Q L$ merupakan suatu perangkat lunak sisem menajemen basis data relasional dengan konsep SQL. SQL (Structured Query Language) adalah sebuah konsep pengoperasian basis data, terutama untuk pemilihan atau seleksi dan pemasukan data, yang memungkinkan pengoperasian data dikerjakan dengan mudah secara otomatis. MySQL merupakan DBMS yang sangat popular sehingga banyak digunakan dalam suatu aplikasi. Beberapa alasan dalam memilih $M y S Q L$ diantaranya sebagai berikut: kecepatan, kemudahan penggunaan, biaya, dukungan bahasa query, kapabilitas, konektivitas dan keamanan, probabilitas, open source, dan multi-user.

\section{ANALISA DAN PEMBAHASAN}

\subsection{Analisa}

Data transaksi penjualan pada suatu usaha penjualan setiap menit, setiap hari, setiap minggu bahkan bertahun-tahun semakin menumpuk dan banyak sekali baik itu dari proses manual maupun proses komputasi yang menyimpan besar sekali sumberdaya komputer. Namun data yang banyak tersebut belum banyak dimanfaatkan dengan baik oleh pengusaha tersebut hanya dibiarkan dan diarsipkan saja bahkan dibuang atau dihapus

Data transaksi penjualan yang banyak dan besar tersebut, dapat dianalisa penjualan dalam hal ketersediaan barang. Barang-barang yang diperlukan untuk tujuan kepuasan pelanggan, dan meningkatkan transaksi penjualan, serta dapat mengetahui perkembangan dari pasar pelanggan yang dapat memenuhi kebutuhannya. Berkaitan dengan hal tersebut, untuk memecahkan masalah tersebut, dibuatlah aplikasi data mining untuk analisis penjualan dengan algoritma apriori berbasis web dengan menggunakan data contoh (sampel data) dari Microsoft Adventure Work.

\subsection{Pembahasan}

\subsubsection{Pola Transaksi Penjualan Adventure Work}

Transaksi yang telah dilakukan, dapat dilihat pola perkembangannya. Pembelian yang dilakukan oleh pembeli dapat dijadikan data acuan untuk membuat analisis persediaan produk selanjutnya. Pada tabel 1, dapat dilihat pola hasil pembacaan transaksi penjualan.

Tabel 1. Contoh hasil pembacaan transaksi penjualan

\begin{tabular}{ccl}
\hline No-ID & ID Order & \\
\hline 1 & 52191 & Mountain Tire Tube, Fender Set - Mountain, Racing Socks, \\
2 & 52192 & Mountain Tire Tube, Sport-100 Helmet, \\
3 & 52193 & Fender Set - Mountain, Sport-100 Helmet, Mountain Tire Tube, Racing Socks \\
4 & 52194 & Fender Set - Mountain, Racing Socks, Mountain Tire Tube, \\
5 & 52195 & Fender Set - Mountain, Racing Socks, \\
6 & 52196 & LL Road Tire, Short-Sleeve Classic Jersey, \\
7 & 52197 & LL Road Tire, Patch Kit/8 Patches \\
8 & 52198 & LL Road Tire, Road Tire Tube, Sport-100 Helmet, Short-Sleeve Classic Jersey \\
9 & 52199 & Touring Tire, Mountain Tire Tube, Long-Sleeve Logo Jersey \\
10 & 52200 & Mountain Tire, LL Road Tire, Patch Kit/8 Patches \\
\hline
\end{tabular}


Proses pembentukan $\mathrm{C} 1$ atau disebut 1 Itemset dengan jumlah minimum support=30\%. Formulasi itemset dapat dituliskan sebagai berikut:

$=\frac{\sum \text { Transaksi Mengandung } A}{\sum \text { Transaksi }} * 100 \%$

Tabel 1. Perhitungan itemset untuk setiap produk

\begin{tabular}{lcc}
\hline \multicolumn{1}{c}{ Itemset } & Jumlah & Support \\
\hline Fender Set - Mountain & 3 & $30 \%$ \\
LL Road Tire & 4 & $40 \%$ \\
Long-Sleeve Logo Jersey & 1 & $10 \%$ \\
Mountain Tire Tube & 5 & $50 \%$ \\
Patch Kit/8 Patches & 2 & $20 \%$ \\
Racing Socks & 3 & $30 \%$ \\
Short-Sleeve Classic Jersey & 2 & $20 \%$ \\
Sport-100 Helmet & 3 & $30 \%$ \\
Touring Tire & 1 & $10 \%$ \\
\hline
\end{tabular}

\subsubsection{Kombinasi 2 Itemset}

Proses pembentukan $\mathrm{C} 2$ atau disebut dengan 2 Itemset dengan jumlah minimum support $=30 \%$ dapat diselesaikan dengan rumus berikut: $\operatorname{Support}(\mathrm{A}, \mathrm{B})=\mathrm{P}(\mathrm{A} \cap \mathrm{B})$

$=\frac{\sum \text { Transaksi Mengandung } A \text { dan } B}{\sum \text { Transaksi }} * 100 \%$

Tabel 3. Contoh hasil seleksi dengan kombinasi 2 itemset

\begin{tabular}{lcc}
\hline Itemset & Jumlah & Support \\
\hline Mountain Tire Tube, Fender Set - Mountain & 3 & $30 \%$ \\
Mountain Tire Tube, Racing Socks, & 2 & $20 \%$ \\
Mountain Tire Tube, Sport-100 Helmet & 2 & $20 \%$ \\
LL Road Tire, Patch Kit/8 Patches & 2 & $20 \%$ \\
Fender Set - Mountain, Racing Socks & 3 & $30 \%$ \\
LL Road Tire, Short-Sleeve Classic Jersey, & 2 & $20 \%$ \\
\hline
\end{tabular}

\subsubsection{Kombinasi 3 Itemset}

Proses pembentukan $\mathrm{C} 3$ atau disebut dengan 3 Itemset dengan jumlah minimum support $=30 \%$ dapat diselesaikan dengan rumus berikut: $\operatorname{Support}(\mathrm{A}, \mathrm{B}, \mathrm{C})=\mathrm{P}(\mathrm{A} \cap \mathrm{B} \cap \mathrm{C})$

$=\frac{\sum \text { Transaksi Mengandung } A_{a} B \text { dan } C}{\sum \text { Transaksi }} * 100 \%$

Tabel 4. Contoh hasil seleksi dengan kombinasi 3 itemset

\begin{tabular}{lcr}
\hline \multicolumn{1}{c}{ Itemset } & Jumlah & Support \\
\hline Mountain Tire Tube, Fender Set - Mountain, Racing Socks, & 2 & $20 \%$ \\
Mountain Tire, LL Road Tire, Patch Kit/8 Patches & 1 & $10 \%$ \\
Touring Tire, Mountain Tire Tube, Long-Sleeve Logo Jersey, & 1 & $10 \%$ \\
LL Road Tire, Road Tire Tube, Sport-100 Helmet & 1 & $10 \%$ \\
LL Road Tire, Road Tire Tube, Short-Sleeve Classic Jersey & 1 & $10 \%$ \\
Fender Set - Mountain, Sport-100 Helmet, Mountain Tire Tube & 1 & $10 \%$ \\
\hline
\end{tabular}

Karena Kombinasi 3 Itemset tidak ada yang memenuhi minimal support, maka 2 kombinasi yang memenuhi untuk pembentukan asosiasi. 


\subsubsection{Pembentukan Aturan Asosiasi}

Setelah semua pola frekuensi tinggi ditemukan, barulah dicari aturan asosiasi yang memenuhi syarat minimum untuk confidence dengan menghitung confidence aturan asosiatif $\mathrm{A} \rightarrow \mathrm{B}$. Minimal Confidence $=60 \%$. Nilai Confidence dari aturan $\mathrm{A} \rightarrow \mathrm{B}$ diperoleh dengan rumus berikut:

Confidence $=\frac{\sum \text { Transaksi Mengandung } A \text { dan } B}{\sum \text { Transaksi } A}$

Dari kombinasi 2 Itemset yang telah ditemukan, dapat dilihat besarnya nilai support, dan confidence dari calon aturan asosiasi seperti tampak pada tabel dibawah ini:

Tabel 4. Hasil confidence dengan minimal confidence $60 \%$

\begin{tabular}{lcc}
\hline \multicolumn{1}{c}{ Aturan } & \multicolumn{2}{c}{ Confidence } \\
\hline Jika membeli Mountain Tire Tube maka akan membeli & 0.6 & $60 \%$ \\
$\begin{array}{l}\text { Fender Set - Mountain } \\
\text { Jika membeli Fender Set - Mountain maka akan membeli } \\
\text { Racing Socks }\end{array}$ & 0.75 & $75 \%$ \\
\hline
\end{tabular}

\section{HASIL}

Tahapan ini memberikan paparan mengenai hasil dari implementasi algoritma apriori dengan bahasa pemrograman berbasis web. Beberapa hasil menunjukan setiap proses yang dilakukan oleh tahapan algoritma apriori. Gambar 4,5,6 menunjukan hasil implementasi pada setiap proses algoritma apriori.

\section{KESIMPULAN}

Penelitian dapat ditarik kesimpulan bahwa dengan diketahuinya produk yang paling banyak terjual, bisa membantu membuatkan aturan asosiasi. Aturan asosiasi ini diperoleh berdasarkan pemilihan Itemset pada setiap transaksi. Dengan demikian hasil yang diperoleh dapat digunakan untuk membantu pengambil keputusan. Hasil lainnya juga, implementasi ini bisa membantu untuk mengadakan stok produk yang banyak disukai oleh pembeli, dan menambah persedian produk.

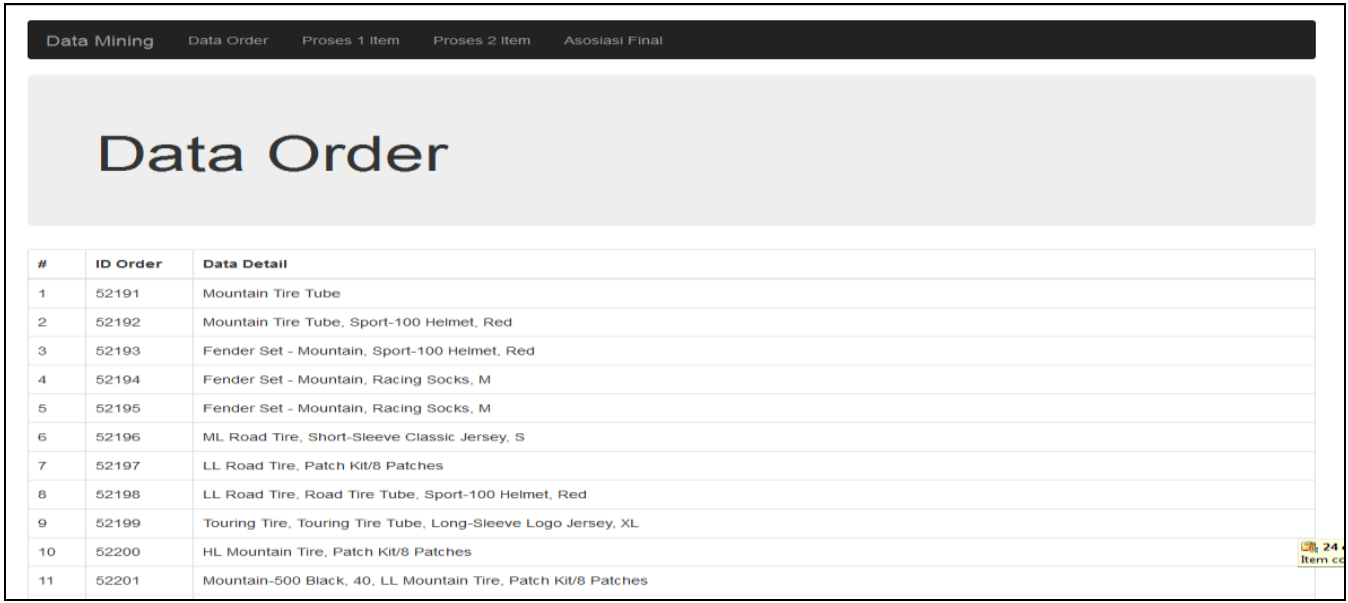

Gambar 2. Antarmuka Penyajian Data Orde Transaksi Penjualan Work 


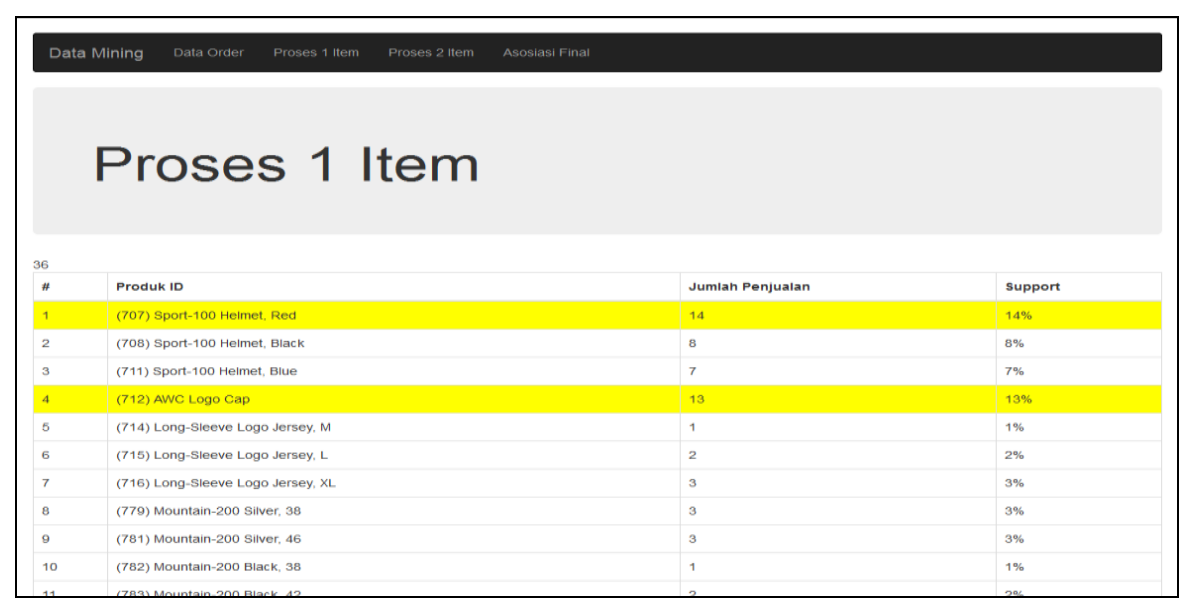

Gambar 3. Contoh Antarmuka Hasil Untuk Itemset Berjumlah 1

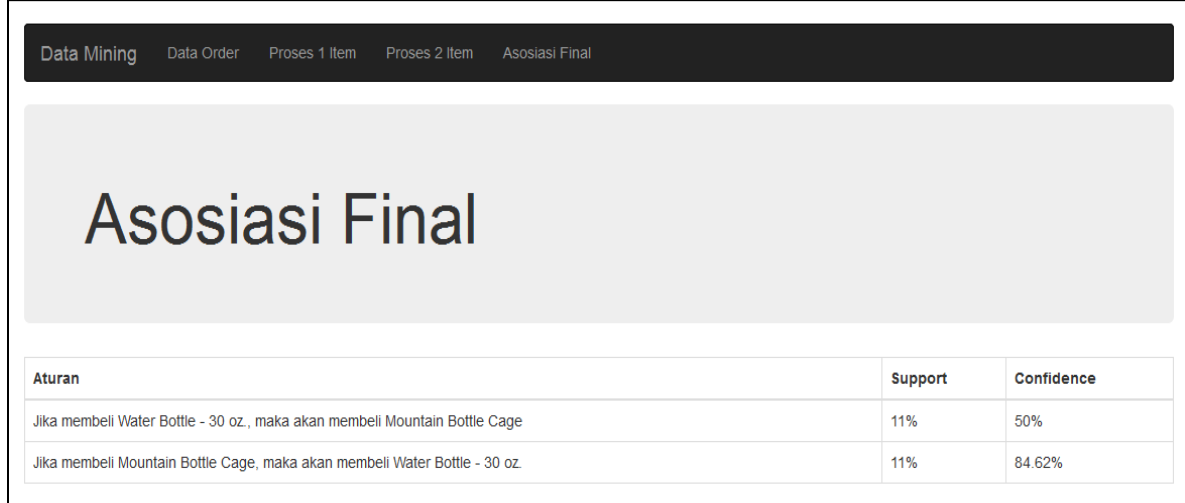

Gambar 4. Antarmuka Hasil Yang Menyajikan Asosiasi Rule Itemset

\section{UCAPAN TERIMA KASIH}

Terima kasih kepada Agis Baswara dan Yana Mulyana yang telah membantu dalam pengumpulan data dan pencarian literasi untuk mendukung penulisan ini.

\section{DAFTAR PUSTAKA}

[1] Boch, Grady, James Rumbraugh, Ivan Jacobson. 1999. Unified Modeling Language (UML). OMG Modeling.

[2] Boehm, Barry W. A Spiral Model for Software Development and Enhancment. Journal volume 21 (61-72)

[3] Pane, D. K. (2013). Implementasi Data mining Pada Penjualan Produk Elektronik Dengan Algoritma Apriori (Studi Kasus: Kreditplus). Pelita Informatika Budi Darma, Volume: IV, Nomor: 3, 25-19.

[4] Kusrini, Emha dan Taufiq Luthfi. (2010). "Algoritma Data Mining", ANDI, Yogyakarta, 2010

[5] Sulianta, Feri dan Juju Dominikus (2010). Data mining: Meramalkan Bisnis Perusahaan. PT Elex Media Komputindo: Jakarta

[6] Kusumo, Dana Sulistiyo, et al. (2003). Data mining Dengan Algoritma Apriori Pada RDBMS Oracle, Jurnal Penelitian dan Pengembangan TELEKOMUNIKASI, Juni 2003, Vol. 8 No.1-3.

[7] Doyle, M. (2010). Beginning PHP 5.3. Indianapolis, USA: Wiley Publishing, Inc. 